\title{
Communication
}

\section{Numerical Simulation Analysis of Fire Hazard from Leakage and Diffusion of Vinyl Chloride in Different Atmospheric Environments}

\author{
Yuchuan Liu (D) and Jian Wang *(D)
}

Citation: Liu, Y.; Wang, J. Numerical Simulation Analysis of Fire Hazard from Leakage and Diffusion of Vinyl Chloride in Different Atmospheric Environments. Fire 2022, 5, 36. https://doi.org/10.3390/fire5020036 Academic Editor: Peter Hamlington Received: 23 December 2021 Accepted: 3 March 2022 Published: 5 March 2022

Publisher's Note: MDPI stays neutral with regard to jurisdictional claims in published maps and institutional affiliations.

Copyright: (c) 2022 by the authors. Licensee MDPI, Basel, Switzerland. This article is an open access article distributed under the terms and conditions of the Creative Commons Attribution (CC BY) license (https:// creativecommons.org/licenses/by/ $4.0 /)$.

\author{
State Key Laboratory of Fire Science, University of Science and Technology of China, Hefei 230026, China; \\ ycliu94@mail.ustc.edu.cn \\ * Correspondence: wangj@ustc.edu.cn; Tel.: +86-551-63606463
}

\begin{abstract}
In this paper, using the numerical simulation analysis software MATLAB and Fire Dynamics Simulation (FDS), the corresponding gas leakage diffusion model and turbulence leakage diffusion module were used to study the diffusion law and fire hazard of vinyl chloride monomer after leakage in different atmospheric environments. The concentration distribution results for vinyl chloride diffusion obtained by numerical simulation were compared and analyzed. The fire hazard area of leakage diffusion is defined by the hot fire concentration of vinyl chloride gas, and the influence of the gas-phase oxidation reaction of vinyl chloride on leakage diffusion is also discussed. The conclusion shows that as the atmospheric environment stabilizes, the peak concentration of vinyl chloride leakage and the diffusion area decrease correspondingly, the fire risk area gradually shrinks, the fire risk decreases, the affected area gradually expands, and the toxicity risk increases. When it is not in a stable state, the formaldehyde derived from the gas-phase oxidation reaction aggregates together with vinyl chloride to form a mixed gas cloud. Although the scope of influence is reduced, the concentration of harmful gases in the area is higher, and the fire risk of the mixed gas is increased.
\end{abstract}

Keywords: vinyl chloride; leakage and diffusion; atmospheric environment; numerical simulation; fire hazard

\section{Introduction}

The petrochemical industry is fundamental to the national economy. In recent years, with the continuous advancement of science and technology, the development trend has become increasingly rapid. Vinyl chloride $\left(\mathrm{C}_{2} \mathrm{H}_{3} \mathrm{Cl}\right)$, as a process gas that is extremely widely used in the fields of fluorine chemicals and polymer chemicals, is a very unstable, flammable, explosive, toxic, and harmful hazardous gas. It is a colorless, liquefiable, and highly fire-prone gas with a boiling point of minus $13.9{ }^{\circ} \mathrm{C}$, a critical temperature of $142^{\circ} \mathrm{C}$, and critical pressure of 5.22 $\mathrm{MPa}$ [1]. Once a large area of leakage occurs, coupled with the external environmental conditions, it rapidly spreads to form a corrosive and toxic gas cloud. When the concentration of vinyl chloride exceeds the concentration of hot fire, if it encounters an open flame or electric spark, it is very likely to cause secondary disasters, such as a fire or explosion [2,3]. This represents a serious threat to the life and safety of personnel and property in the leakage area, leads to shutdowns and environmental damage, causes huge economic losses, and places great pressure on accident-handling, evacuation, rescue operations.

Poisoning and even explosion accidents caused by the leakage and diffusion of vinyl chloride are not uncommon [4,5]. In 2004, a leak occurred in the vinyl chloride polymerization unit at the Formosa Plastics Plant in Illinois, USA [6]. The vinyl chloride monomer exploded, and the fire spread and ignited a nearby PVC (Polyvinyl chloride) warehouse. The accident eventually caused five deaths and three serious injuries. In 2018, a leak occurred in the vinyl chloride gas tank of Shenghua Company in Hebei Province, China [7]. 
The leaked gas quickly spread to the roads surrounding the plant and exploded in an open flame. The accident caused 23 deaths and 22 injuries, including vehicle drivers on both sides of the road.

Many researchers have studied the leakage and diffusion of vinyl chloride and other gases by using simulation software, such as FDS and MATLAB. In 2015, Huang et al. [8] used FDS software tools to simulate and study the variation law of ammonia leakage and diffusion concentration with time and space, which was essentially consistent with the results of theoretical calculations, and they verified the feasibility of FDS simulation. In 2016, Wang et al. [9] used MATLAB simulation software and the Gaussian plume model to study the influencing factors of the leakage and diffusion of a liquid ammonia storage tank and determine the dangerous area of liquid ammonia diffusion poisoning. In 2019, Liu et al. [10] used ALOHA software to simulate and analyze the influence of the size of the leakage opening of a vinyl chloride storage tank and the environmental wind speed on its leakage spread and explosion hazard zone. In 2019, Xing et al. [11] used FLUENT software to simulate and analyze the flow field after the leakage and diffusion of vinyl chloride and to study the impact of environmental wind speed on the consequences of the leakage and diffusion of vinyl chloride. Foreign scholars conducted earlier studies on the law and mechanism of gas leakage and diffusion [12,13]. In 2019, Majumdar et al. [14] used the ISC-AERMOD diffusion model to analyze the concentration distribution of pollutant components in the air around a refinery and study their impact on ambient air quality. Full-scale experimental research in the 1970s and 1980s was also relatively comprehensive and in-depth, including the proposed and continuously optimized leakage diffusion model, etc. $[15,16]$, whereas research on vinyl chloride was more focused on its diffusion in water or PVC production media or on its law and reaction mechanism. In general, research on the leakage and diffusion of vinyl chloride gas mainly focuses on the initial conditions and the influence of environmental factors, the characteristics and mechanism of explosions, the analysis of environmental human hazards and the extent of accident damage, etc., and related research on the consequences of its gas-phase reaction. There is relatively little work in this field.

Vinyl chloride produces a photochemical smog reaction in the atmosphere, and its strong volatility causes it to be easily photodegraded in the atmosphere, which is also its main degradation pathway. In the gas phase, vinyl chloride is partially oxidized to form formaldehyde, formic acid, and hydrogen chloride, and its conversion rate is affected by the degree of atmospheric stability. Therefore, in this paper, we selected the corresponding gas diffusion theoretical model and turbulence leakage diffusion model and used the numerical simulation analysis software MATLAB and FDS to deeply study the diffusion law and accident evolution characteristics of vinyl chloride under different levels of atmospheric stability, and analyzed the risk of its leakage and diffusion. The development trend and hazard prediction of vinyl chloride leakage accidents are very important for the safe production and application of vinyl chloride in chemical enterprises, leakage prevention management, emergency treatment after accidents, rescue and evacuation, etc.

\section{Leakage Diffusion Simulation Analysis}

\subsection{Diffusion Theory Model}

There are many processes of gas leakage and diffusion, and the mechanism is very complicated. Beginning in the 1970s, research scholars in developed countries. such as European countries and the United States, began to study and successively propose mathematical theories of leakage and diffusion related to various specific assumptions. After gradual improvement, some fairly mature diffusion theory models were finally formed-for example, the Gaussian model, BM diffusion model, Sutton diffusion model, FEM3 diffusion model, box and similar models, shallow diffusion model, plate model, ISC-AERMOD model [13], etc.

The Gaussian model is widely used due to its simplicity, numerical accuracy, and easy calculation. Therefore, the Gaussian plume sub-model was selected for this study, 
combined with MATLAB software for numerical analysis. We also discussed the gas cloud change and concentration distribution characteristics of vinyl chloride after leakage and diffusion under different levels of atmospheric stability.

The Gaussian plume model is used to describe the formation process of the continuous leakage and diffusion of a smoke cloud and the spatial concentration distribution when the gas cloud is stable [17]. The model sets the space coordinate system according to the right-hand rule of the environmentally dominant wind direction, selects the center position of the vinyl chloride leakage as the spatial origin, and takes the positive $x$-axis direction as the environmentally dominant wind direction, and the settings of the y-axis and z-axis follow the right-hand rule to characterize the steady state of continuous leakage. The formula of the Gaussian plume model is expressed in Formula (1):

$$
C(x, y, z, H)=\frac{Q}{2 \pi u \sigma_{y} \sigma_{z}} \cdot e^{-\frac{y^{2}}{2 \sigma_{y}^{2}}} \cdot\left(e^{-\frac{(z-H)^{2}}{2 \sigma_{z}^{2}}}+e^{-\frac{(z+H)^{2}}{2 \sigma_{z}^{2}}}\right)
$$

The parameters in Formula (1) and their meanings are shown in Table 1.

Table 1. Gaussian diffusion formula parameters.

\begin{tabular}{|c|c|c|}
\hline Parameters & Units & Meanings \\
\hline $\mathrm{C}(\mathrm{x}, \mathrm{y}, \mathrm{z}, \mathrm{H})$ & $\mathrm{g} / \mathrm{m}^{3}$ & $\begin{array}{l}\text { The concentration value of the stable gas cloud after the } \\
\text { leakage and diffusion of vinyl chloride at the spatial } \\
\text { coordinates }(x, y, z)\end{array}$ \\
\hline $\mathrm{H}$ & $\mathrm{m}$ & $\begin{array}{l}\text { The effective height of the leakage source, which is usually } \\
\text { the sum of the height of the leakage outlet from the ground, } \\
\mathrm{H}_{\mathrm{r}} \text {, and the flue gas rise height } \Delta \mathrm{H} \text {, i.e., } \mathrm{H}=\mathrm{H}_{\mathrm{r}}+\Delta \mathrm{H}\end{array}$ \\
\hline Q & $\mathrm{kg} / \mathrm{s}$ & $\begin{array}{c}\text { The source strength of the leakage source, also known as the } \\
\text { leakage rate }\end{array}$ \\
\hline $\mathrm{u}$ & $\mathrm{m} / \mathrm{s}$ & $\begin{array}{c}\text { The average wind speed in the direction of the external } \\
\text { environment dominating the wind, usually taken as the } \\
\text { elevation of wind speed value at } 10 \mathrm{~m}\end{array}$ \\
\hline$\sigma_{\mathrm{y}}$ & $\mathrm{m}$ & $\begin{array}{l}\text { The diffusion coefficient orthogonal to the } x \text {-axis, i.e., the } \\
\text { vertical direction of the main wind direction }\end{array}$ \\
\hline$\sigma_{\mathrm{z}}$ & $\mathrm{m}$ & $\begin{array}{l}\text { The diffusion coefficient in the plumb direction orthogonal } \\
\text { to the horizontal plane }\end{array}$ \\
\hline
\end{tabular}

The classification of atmospheric stability is determined by reference to many factors, such as environmental wind speed, degree of sunshine, day and night, degree of overcast cloud cover, and weather conditions. Refer to Table 2 for specific selection $[18,19]$.

Table 2. Atmospheric stability class.

\begin{tabular}{|c|c|c|c|c|c|c|}
\hline \multirow[b]{2}{*}{$\begin{array}{c}\text { Ambient } \\
\text { Wind Speed } \\
(\mathrm{m} / \mathrm{s})\end{array}$} & \multicolumn{3}{|c|}{ Daytime Sunshine } & \multirow[b]{2}{*}{$\begin{array}{c}\text { Cloudy Day } \\
\text { or Night }\end{array}$} & \multicolumn{2}{|c|}{ Night } \\
\hline & Strong & Moderate & Weak & & $\begin{array}{c}\text { Low Thin } \\
\text { Cloud } \\
\geq 0.5\end{array}$ & $\begin{array}{l}\text { Cloudiness } \\
\leq 0.375\end{array}$ \\
\hline$<2$ & A & $A \sim B$ & B & $\mathrm{D}$ & $\mathrm{F}$ & $\mathrm{F}$ \\
\hline $2 \sim 3$ & $A \sim B$ & B & $\mathrm{C}$ & $\mathrm{D}$ & E & F \\
\hline $3 \sim 5$ & B & $\mathrm{B} \sim \mathrm{C}$ & C & $\mathrm{D}$ & $\mathrm{D}$ & E \\
\hline $5 \sim 6$ & $\mathrm{C}$ & $C \sim D$ & $\mathrm{D}$ & $\mathrm{D}$ & $\mathrm{D}$ & $\mathrm{D}$ \\
\hline$>5$ & $\mathrm{C}$ & $\mathrm{D}$ & $\mathrm{D}$ & $\mathrm{D}$ & $\mathrm{D}$ & $\mathrm{D}$ \\
\hline
\end{tabular}

The Pasquil-Gifford model is used to determine the diffusion coefficient. The value of the diffusion coefficient, $\sigma_{y}, \sigma_{z}$, is related to the degree of atmospheric stability in Table 1. Therefore, when the degree of atmospheric stability has been selected, the difference between the rural and urban diffusion environments can be calculated. Please refer to Table 3 to select the diffusion coefficient in the Gaussian plume model $[19,20]$. 
Table 3. Diffusion coefficient of the Gaussian plume model.

\begin{tabular}{|c|c|c|c|}
\hline Atmospher & Class & $\sigma_{y}(\mathrm{~m})$ & $\sigma_{\mathrm{z}}(\mathrm{m})$ \\
\hline \multirow{5}{*}{ Rural conditions } & A & $\frac{0.22 \mathrm{x}}{(1+0.0001 \mathrm{x})^{0.5}}$ & $0.22 x$ \\
\hline & B & $\frac{0.16 \mathrm{x}}{(1+0.0001 \mathrm{x})^{0.5}}$ & $0.12 x$ \\
\hline & C & $\frac{0.11 x}{(1+0.0001 x)^{0.5}}$ & $\frac{0.08 \mathrm{x}}{(1+0.0002 \mathrm{x})^{0.5}}$ \\
\hline & $\mathrm{D}$ & $\frac{0.08 \mathrm{x}}{(1+0.0001 \mathrm{x})^{0.5}}$ & $\begin{array}{c}(1+0.0015 x)^{0.5} \\
0.03 x\end{array}$ \\
\hline & $\mathrm{E}$ & $\begin{array}{c}(1+0.0001 x)^{0.5} \\
0.04 x \\
\end{array}$ & $\begin{array}{c}\frac{0.03 \mathrm{x}}{(1+0.0003 \mathrm{x})^{0.5}} \\
0.016 \mathrm{x}\end{array}$ \\
\hline \multirow{4}{*}{ Town conditions } & $A \sim B$ & $\begin{array}{l}\frac{(1+0.0001 x)^{0.5}}{0.32 x} \\
\frac{(1+0.0001 x)^{0.5}}{}\end{array}$ & $\begin{array}{c}(1+0.0003 x)^{0.5} \\
0.24 x \\
\end{array}$ \\
\hline & C & $\frac{0.22 \mathrm{x}}{(1+0.0001 \mathrm{x})^{0.5}}$ & $\begin{array}{c}(1+0.0001 \mathrm{x})^{0.5} \\
0.20 \mathrm{x}\end{array}$ \\
\hline & $\mathrm{D}$ & $\frac{0.16 \mathrm{x}}{0.5}$ & \multirow{2}{*}{$\frac{0.14 x}{(1+0.0003 x)^{0.5}} \frac{0.08 x}{(1+0.0015 x)^{0.5}}$} \\
\hline & $\mathrm{E} \sim \mathrm{F}$ & $\frac{(1+0.0001 x)^{0.11 x}}{(1+0.0001 x)^{0.5}}$ & \\
\hline
\end{tabular}

\subsection{MATLAB Numerical Analysis}

Using MATLAB numerical analysis software and the Gaussian plume model, we examined the spatial distribution of the concentration field of the vinyl chloride monomer at different atmospheric stability classes, from unstable to stable, namely class A, C, and E, and performed continuous leakage simulation analysis.

The simulation adopts a three-dimensional coordinate system, takes the coordinate origin as the leakage source, and sets the area $200 \mathrm{~m}$ downwind and $100 \mathrm{~m}$ crosswind as the main leakage investigation range.

Based on the actual site conditions of a chemical plant and the setting parameters of the vinyl chloride storage device, the model sets the leakage intensity of the vinyl chloride monomer leakage source as $Q=8 \mathrm{~kg} / \mathrm{s}$, and the vertical ground leakage is upwards. The average wind speed in the dominant wind direction of the regional environment is $\mathrm{u}=3 \mathrm{~m} / \mathrm{s}$. The sum of height of leakage outlet from the ground, $\mathrm{H}_{\mathrm{r}}=2 \mathrm{~m}$, and the rising height of flue gas $\Delta \mathrm{H}=5 \mathrm{~m}$, so the effective height of the leakage source is $\mathrm{H}=7 \mathrm{~m}$. Referring to Table 2, the atmospheric stability class and diffusion coefficient shown in Table 4 were adopted in combination with the leakage source.

Table 4. Diffusion coefficient at different atmospheric stabilities.

\begin{tabular}{ccc}
\hline Atmospheric Stability & $\sigma_{\mathbf{y}}(\mathbf{m})$ & $\sigma_{\mathbf{z}}(\mathbf{m})$ \\
\hline A & $\sigma_{\mathrm{y}}=\frac{0.22 \mathrm{x}}{(1+0.0001 \mathrm{x})^{0.5}}$ & $\sigma_{\mathrm{z}}=0.20 \mathrm{x}$ \\
C & $\sigma_{\mathrm{y}}=\frac{0.111 \mathrm{x}}{(1+0.0001 \mathrm{x})^{0.5}}$ & $\sigma_{\mathrm{z}}=\frac{0.08 \mathrm{x}}{(1+0.0002 \mathrm{x})^{0.5}}$ \\
E & $\sigma_{\mathrm{y}}=\frac{0.0661 \mathrm{x}}{(1+0.0001 \mathrm{x})^{0.5}}$ & $\sigma_{\mathrm{z}}=\frac{0.03 \mathrm{x}}{(1+0.0003 \mathrm{x})^{0.5}}$ \\
\hline
\end{tabular}

In terms of fire and explosion risk of vinyl chloride, it forms an explosive mixture with air, the explosion limit is 3.6 33\% (volume), and the lower flammability limit (LFL) value of vinyl chloride is $3.6 \%$. Considering that there are many open fires or electric sparks of electrical equipment in actual production, vinyl chloride may burn and cause fire before reaching the lower explosion limit. Therefore, according to the safety regulations for hot work in plants, the hot work concentration of vinyl chloride gas is $0.4 \%$ (volume). Combined with the density of vinyl chloride, the hot work concentration is $8.62 \mathrm{~g} / \mathrm{m}^{3}$. The leakage of vinyl chloride storage devices is generally large, so the fire hazard area is defined by the fire concentration.

The numerical analysis results of continuous leakage of vinyl chloride monomer at different atmospheric stability classes, A, C, and E, are given below. The $\mathrm{x}$-axis indicates the distance from the downwind direction of the leakage source, the y-axis indicates the distance from the side wind direction of the leakage source, and the z-axis indicates the gas 
diffusion concentration at this position. The color changes from blue to orange, indicating that the concentration value changes from low to high.

When the vinyl chloride monomer leaks continuously, the vinyl chloride sprayed from the leak is gradually diffused under the influence of the stability of the external environment, and at the same time, it is continuously supplemented by the leak source; finally, a stable vinyl chloride vapor cloud is formed. The change in its concentration is shown in Figure 1. There is a large difference in the concentration of vinyl chloride under different levels of atmospheric stability. When the atmospheric stability is class $\mathrm{A}$, the concentration distribution on the horizontal plane is similar to that of a bullhorn, and there is almost no gentleness around it. The transition zone and the more stable class $\mathrm{C}$ and stable class E concentration distribution types are similar to a hump shape, with a higher and sharper peak area; there is also a gentle transition area, the center is high, and the surrounding area is low.

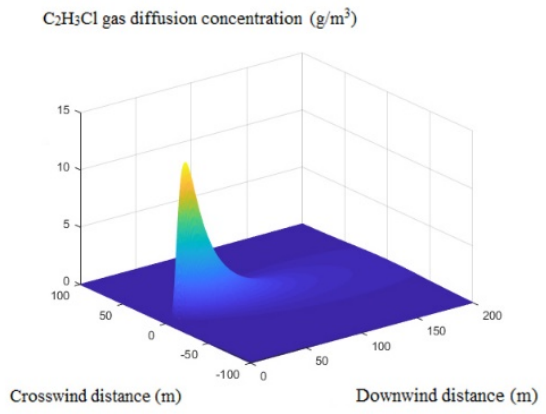

(a)

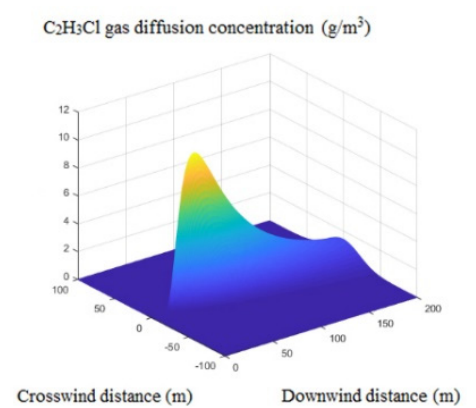

(b)

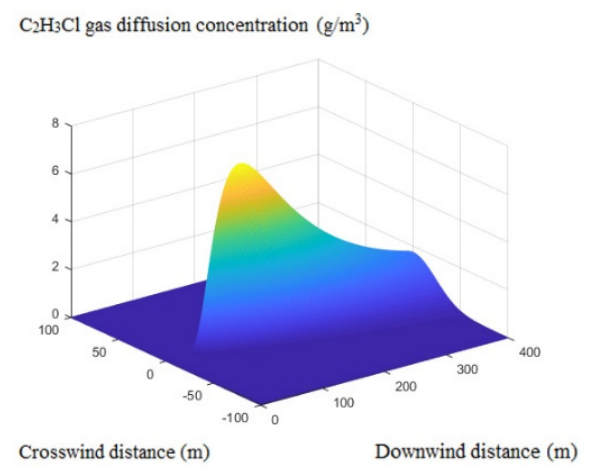

(c)

Figure 1. Graph of the concentration changes of vinyl chloride at a height of $2 \mathrm{~m}$ from the leak source under different atmospheric stabilities. (a) Concentration when atmospheric stability is class A. (b) Concentration when atmospheric stability is class C. (c) Concentration when atmospheric stability is class $\mathrm{E}$.

When other conditions are stable and only the degree of atmospheric stability is changed, the concentration of vinyl chloride leaks and eventually forms a stable vinyl chloride gas cloud that changes significantly. As the degree of atmospheric stability changes from unstable to stable, i.e., from A to E, the vapor cloud is gradually weakened by convection and other fluctuations, from an unstable, small-scale, high-risk concentration area to a region with the main wind directed upwards. In the case of elongated crosswinds widening upwards and when the concentration in the central agglomeration area decreases, the concentration area distribution changes from an ellipse with a smaller focal length to a prolate ellipse. According to the hot fire concentration of vinyl chloride gas of $8.62 \mathrm{~g} / \mathrm{m}^{3}$, the regional distribution of fire hazard concentration when different atmospheric stability 
classes A, C, and E are defined is shown in Figure 2. Table 5 below shows the distribution of high-concentration hazardous areas.

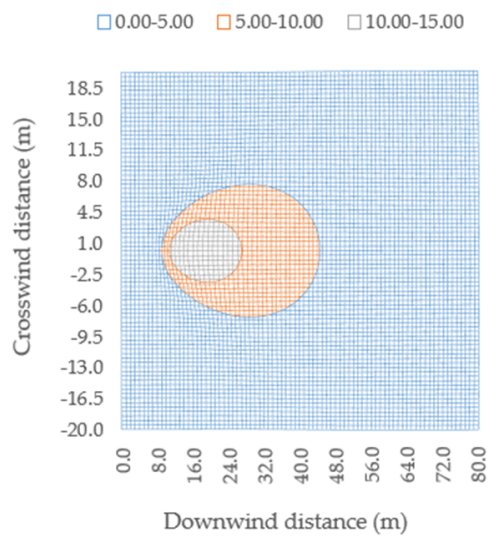

(a)

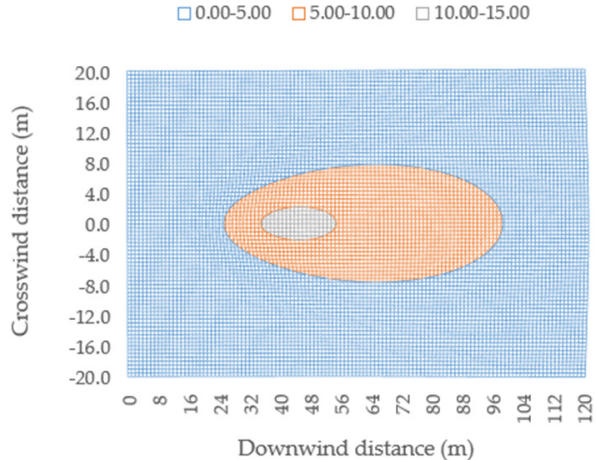

(b)

Crosswind distance $(\mathrm{m})$

$\square 0.00-2.00 \quad \square 2.00-4.00 \quad \square 4.00-6.00 \quad \square 6.00-8.00$

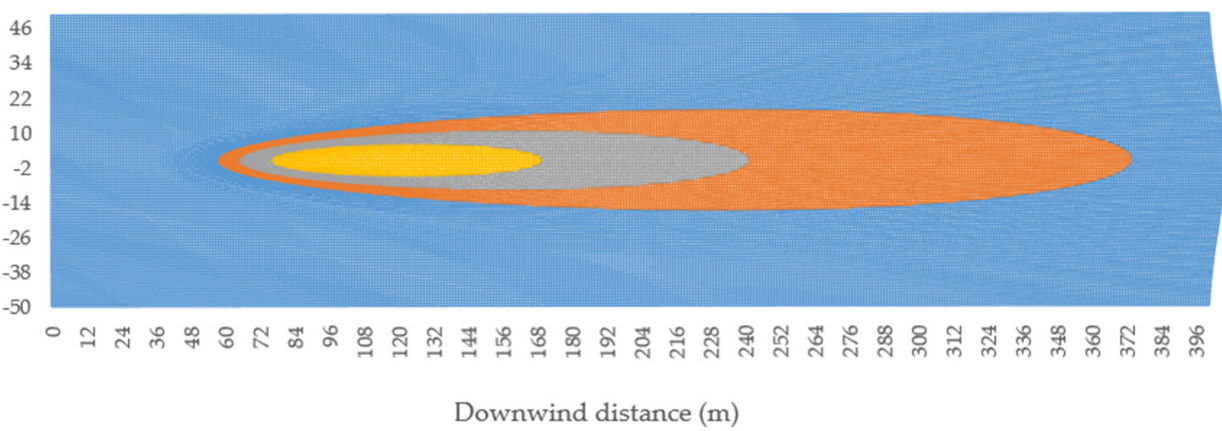

(c)

Figure 2. Regional distribution map of vinyl chloride concentration at a height of $2 \mathrm{~m}$ from the leak source with different atmospheric stabilities. (a) Concentration when atmospheric stability is class A $\left(\mathrm{g} / \mathrm{m}^{3}\right)$. (b) Concentration when atmospheric stability is class $\mathrm{C}\left(\mathrm{g} / \mathrm{m}^{3}\right)$. (c) Concentration when atmospheric stability is class $\mathrm{E}\left(\mathrm{g} / \mathrm{m}^{3}\right)$.

Table 5. Distribution of high-concentration hazardous areas.

\begin{tabular}{|c|c|c|c|c|}
\hline \multirow{2}{*}{ Atmospheric Stability } & \multirow{2}{*}{$\begin{array}{c}\text { Maximum } \\
\text { Concentration } \\
\text { Value }\left(\mathrm{g} / \mathrm{m}^{3}\right)\end{array}$} & \multirow{2}{*}{$\begin{array}{c}\text { Highest Concentration } \\
\text { Value Position } \\
\text { (Leakage Source from } \\
\text { Downwind Direction (m)) }\end{array}$} & \multicolumn{2}{|c|}{ Concentration Exceeding Area } \\
\hline & & & $\begin{array}{l}\text { Downwind Distance } \\
(\mathrm{m})\end{array}$ & $\begin{array}{l}\text { Crosswind Distance } \\
(\mathrm{m})\end{array}$ \\
\hline $\mathrm{A}$ & 13.64 & 17.5 & $12 \sim 31$ & 4 \\
\hline $\mathrm{C}$ & 10.88 & 44.5 & $33 \sim 65$ & 3.5 \\
\hline $\mathrm{E}$ & 7.41 & 119.5 & - & - \\
\hline
\end{tabular}

Analyzing Figure 3, along the main wind direction, as the distance from the leakage source increases, the concentration of vinyl chloride increases rapidly and reaches the highest concentration, and then gradually decreases until it is completely diluted by air. As the atmospheric stability changes from unstable to stable, from $A$ to $E$ in the main wind direction, the distance from the concentration peak to the leakage source gradually increases, the maximum concentration of the leakage area decreases, the downward trend after the peak slows down, and the influence area is larger. 


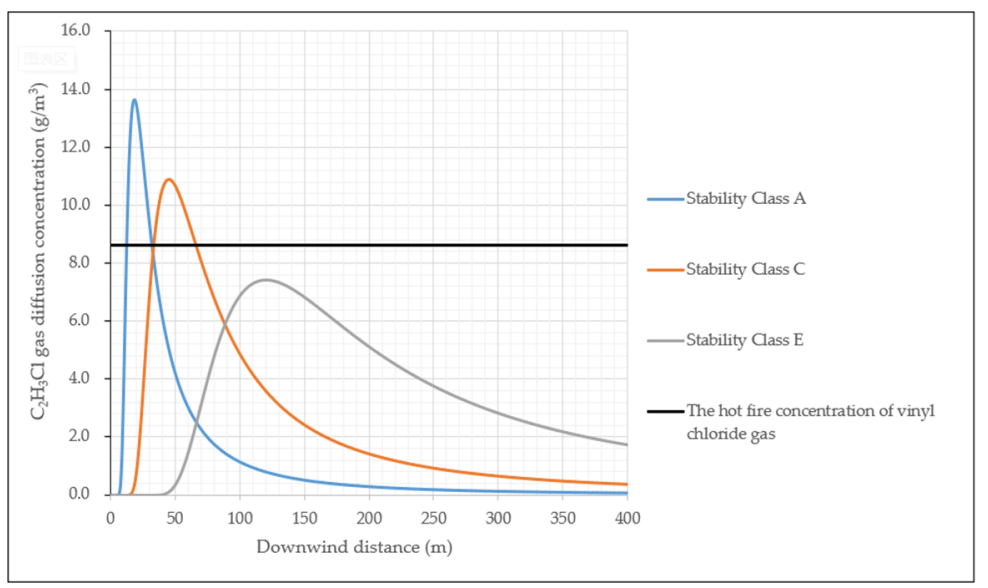

Figure 3. Diagram of concentration changes of the main wind direction of vinyl chloride at a height of $2 \mathrm{~m}$ from the leakage source with a stable atmosphere.

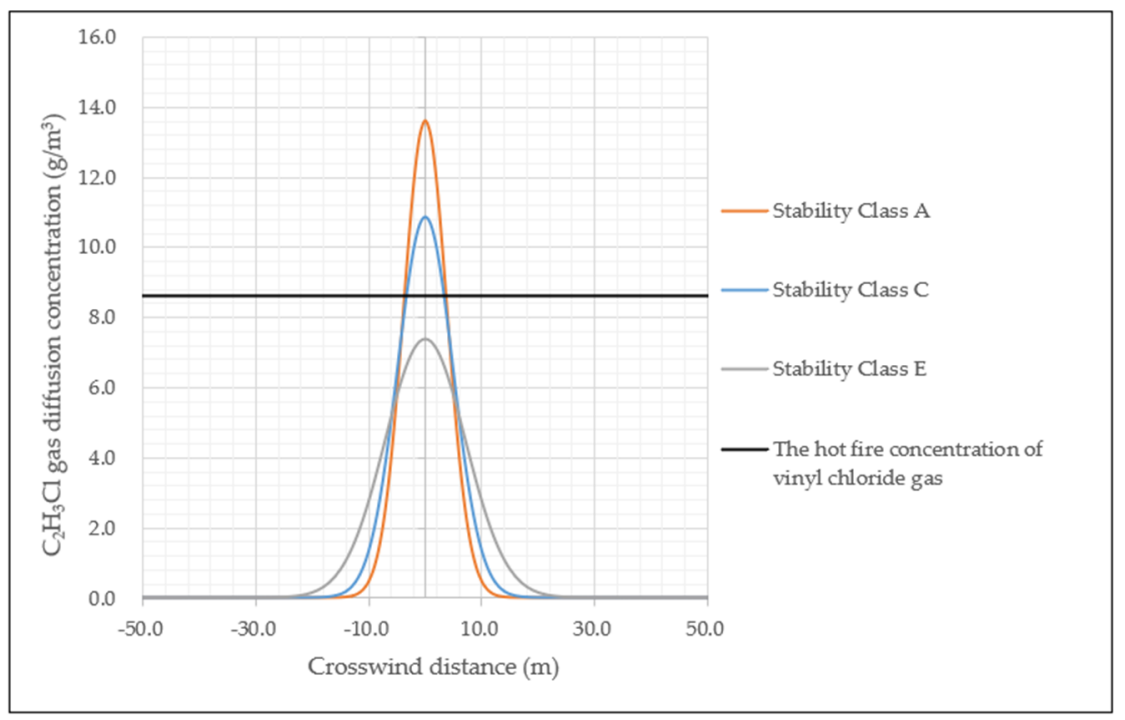

Figure 4. Concentration changes in crosswind direction of vinyl chloride under different atmospheric stabilities.

Analyzing Figure 4, as the distance from the leakage source increases in the crosswind direction, in a symmetrical concentration distribution field, the peak concentration of vinyl chloride is consistent with the upward change of the main wind, and the central concentration value is the highest. This trend is essentially the same as the prevailing trend. As the degree of atmospheric stability changes from unstable to stable, i.e., from A to E, the upward and downward trend slows down, the maximum concentration value in the crosswind direction continues to decrease, the area of toxic hazard becomes narrowed, and the scope of influence is gradually expanded.

As the degree of atmospheric stability changes from unstable to stable, i.e., from A to $C$ to $E$, and the vinyl chloride vapor cloud is gradually weakened by convection and other fluctuations, it changes from an unstable, small-scale, high-risk concentration area to a situation in which the area in the main wind is elongated, the crosswind is widened, the concentration in the central agglomeration area decreases, and the distribution of the concentration area changes from an ellipse with a smaller focal length to a prolate ellipse. As the atmospheric environment changes from a highly unstable state to a relatively stable state, the peak concentration of vinyl chloride in the leakage diffusion area of vinyl chloride 
gradually decreases, the fire risk gradually decreases, the fire risk area shrinks, and the toxic risk area continues to expand.

\subsection{FDS Numerical Simulation}

Vinyl chloride reacts with oxygen in the air in the gas phase, and the reaction equation is expressed in Formula (2). Vinyl chloride $\left(\mathrm{C}_{2} \mathrm{H}_{3} \mathrm{Cl}\right)$ and oxygen $\left(\mathrm{O}_{2}\right)$ react under atmospheric, light, and other relevant conditions to produce formaldehyde ( $\mathrm{HCHO})$, formic acid $(\mathrm{CHOOH})$, and hydrogen chloride $(\mathrm{HCl})$.

$$
\mathrm{C}_{2} \mathrm{H}_{3} \mathrm{Cl}+\mathrm{O}_{2} \rightarrow \mathrm{HCHO}+\mathrm{CHOOH}+\mathrm{HCl}
$$

Under normal conditions, formic acid and hydrogen chloride liquefy to form a white, droplet-like acidic mist. After the formation of toxic formaldehyde gas, it diffuses together with the leaked vinyl chloride. We investigated a case wherein the atmospheric environment is unstable, there is low atmospheric pressure and weak ambient wind, light and other conditions dominate, and the conversion rate of the oxidation reaction increases accordingly. At this time, we consider the reaction and the mixture to participate in the diffusion; when the atmospheric environment is stable, the influence of sunshine, etc., is relatively weak, and the wind speed becomes the dominant factor. At this time, only pure vinyl chloride is involved in the diffusion.

Using FDS numerical simulation software, referring to the technical manual of FDS, the effective height of the vinyl chloride monomer leakage source was set to $2 \mathrm{~m}$, the leakage rate $\mathrm{V}=3.05 \mathrm{~m}^{3} / \mathrm{s}$, and the vertical ground leaked upward. We set a $300 \mathrm{~m} \times 100 \mathrm{~m} \times 20 \mathrm{~m}$ rectangular parallelepiped open-space grid with a grid spacing of $0.5 \mathrm{~m}$, and the leakage source was a surface source of $0.2 \mathrm{~m} \times 0.2 \mathrm{~m}$. We performed a numerical simulation of the spatial distribution of the concentration field of the non-point source of vinyl chloride monomer leakage under different atmospheric stability classes and continuous leakage.

When the atmospheric environment is unstable, conditions such as low air pressure, weak ambient wind, and light are dominant. The partial photolysis of vinyl chloride produces gaseous formaldehyde, and its partial conversion rate is approximately $20 \%$. The reaction proceeds evenly in the gas cloud. After the mixed gas diffuses together, the yellow represents the boundary of the over-standard area. The concentration distribution of vinyl chloride after leakage and diffusion according to the simulation is shown in Figure 5.

When the atmospheric environment is unstable, the leaked vinyl chloride diffuses and gradually forms a gas cloud, and at the same time, a uniform gas-phase oxidation reaction occurs, accompanied by the formation of a formaldehyde gas cloud. The whole presents a distribution pattern with a high concentration of leakage source and diffusion edge and a low concentration in the middle area. As the diffusion time increases, the central high-concentration area diffuses, and the whole extends outward. Although the concentration of the formaldehyde gas cloud is lower than that of vinyl chloride, it is still considerably high. The area is more obvious and has a larger range.

When the atmospheric environment is stable, the influence of the atmosphere, sunshine, etc., is weak, and wind speed becomes the dominant factor. Only the diffusion of pure vinyl chloride and the leakage of vinyl chloride monomer were considered. We took the regional environmental average wind speed, $\mathrm{u}=3 \mathrm{~m} / \mathrm{s}$, and the concentration distribution after leakage and diffusion, as the figure below shows. The $\mathrm{x}$-axis indicates the distance from the downwind direction of the leakage source, the y-axis indicates the distance from the side wind direction of the leakage source, and the z-axis indicates the gas diffusion concentration at this position. The color changes from blue to red, indicating that the concentration value changes from low to high. 

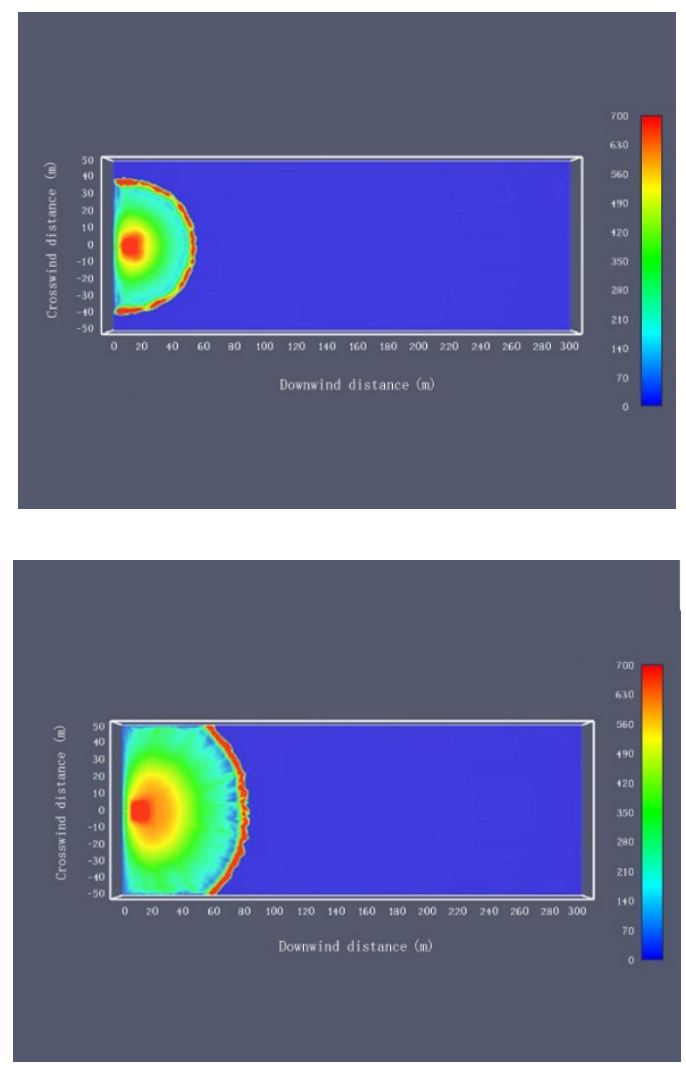

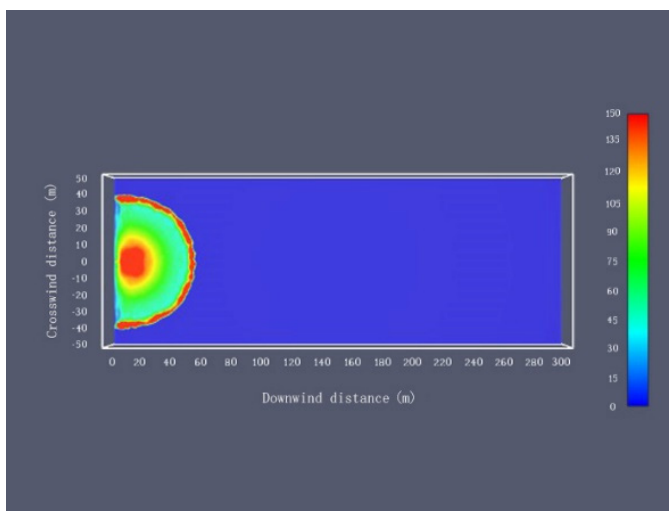

(a)

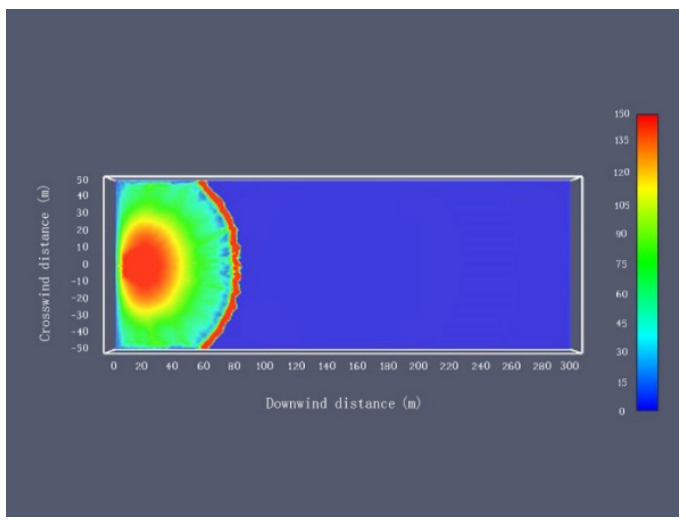

(b)

Figure 5. Z-plane $(\mathrm{H}=2 \mathrm{~m})$ diffusion concentration area distribution map when the atmosphere is unstable (top view). (a) Concentration distribution of vinyl chloride (left) and formaldehyde (right) at $\mathrm{t}=60 \mathrm{~s}$. (b) Concentration distribution ( $\mathrm{ppm}$ ) of vinyl chloride (left) and formaldehyde (right) at $\mathrm{t}=120 \mathrm{~s}$.

It can be seen from the change trend in Figure 6 that when the atmospheric environment is stable, the effect of the diffusion trend of vinyl chloride is relatively obvious when there is no wind. The downwind side is fan-shaped, and the end is semicircular, extending outward, whereas the crosswind direction gradually expands to the maximum width. The gas cloud is distributed symmetrically along the axis as a whole, with the highest concentration at the center of the leakage source and a thread-like high-concentration zone along the wind direction, which lengthens with diffusion time.

Compared with when the atmospheric environment is unstable, the wind speed has a significant impact on the form, speed, range, and concentration distribution of the gas cloud formed by the leakage and diffusion of vinyl chloride. When the atmospheric environment is unstable, vinyl chloride is relatively concentrated after leakage. Although the scope of influence is small, toxic formaldehyde has a stronger agglomeration effect and is difficult to handle, which increases the number of harmful gases in the area. In addition, the mixed gas of formaldehyde and air is flammable and explosive, and the risk of fire is greater. In actual diffusion, the reaction also generates an acidic mist of formic acid and hydrochloric acid, which is very harmful [21]. 


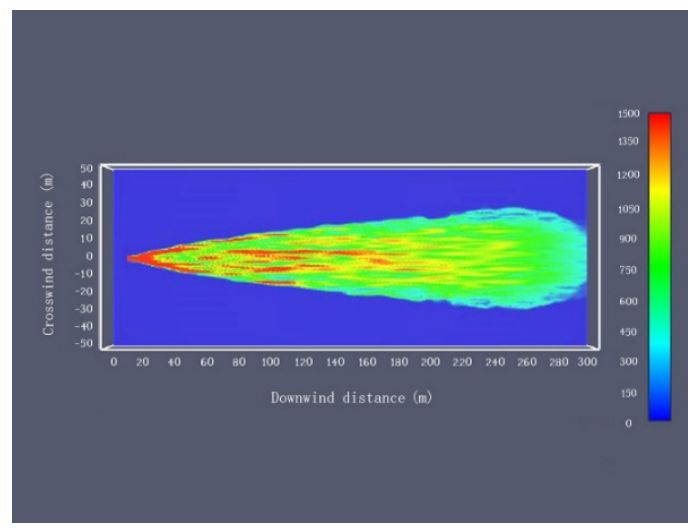

(a)

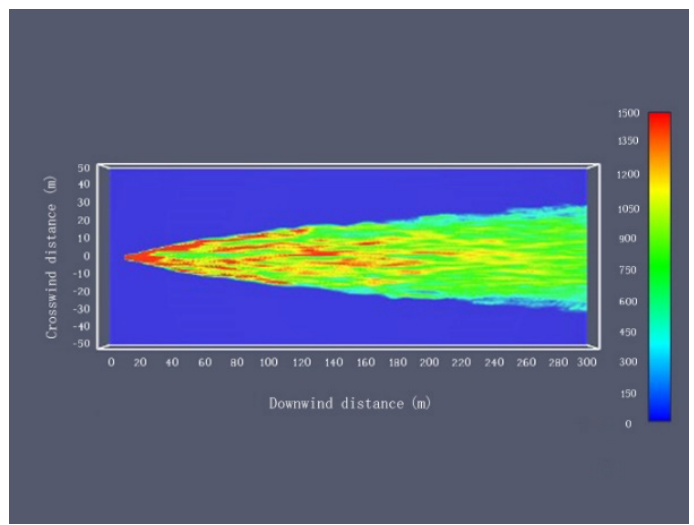

(b)

Figure 6. Distribution map of the diffusion concentration in the $\mathrm{Z}$ plane $(\mathrm{H}=2 \mathrm{~m})$ when the atmospheric environment is stable at $t=60$ and $120 \mathrm{~s}$ (top view). (a) Concentration distribution of vinyl chloride in the $\mathrm{Z}$ plane at $\mathrm{t}=60 \mathrm{~s}(\mathrm{ppm})$. (b) Concentration distribution of vinyl chloride in the $\mathrm{Z}$ plane at $\mathrm{t}=120 \mathrm{~s}(\mathrm{ppm})$.

\section{Discussion}

The concentration distribution results of two different simulation methods in the main wind direction were processed to obtain Figure 7.

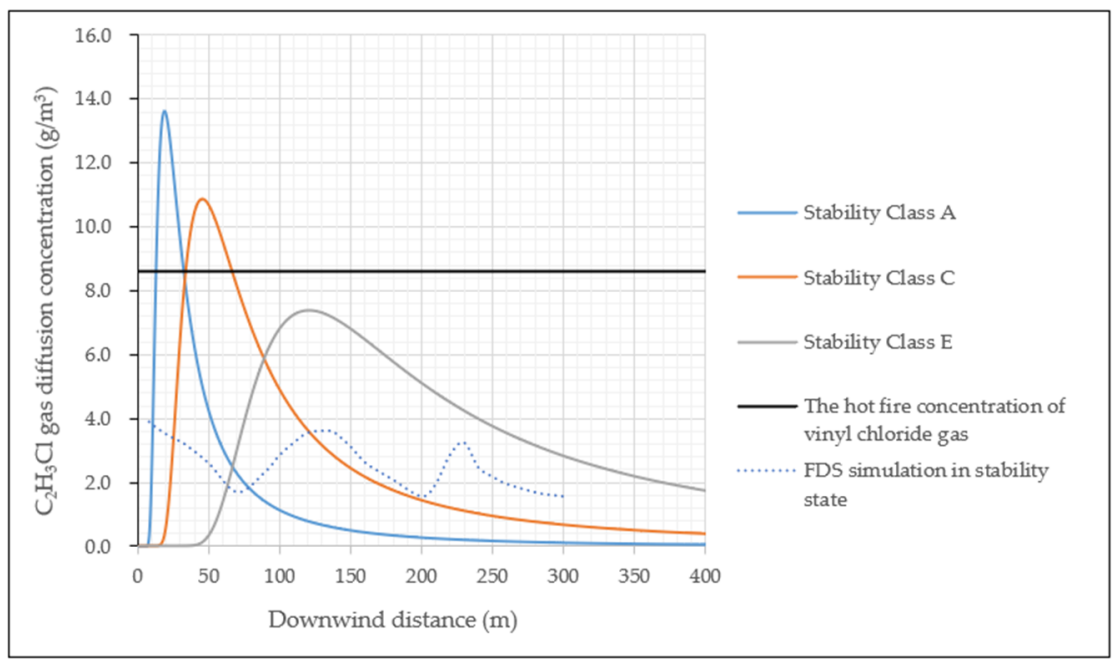

Figure 7. Concentration distribution diagram of MATLAB and FDS simulation methods in downwind direction.

Comparing the numerical analysis results of MATLAB, when the atmospheric stability is poor, the diffusion of vinyl chloride shows the characteristics of small range and high concentration. Under the Gaussian plume model, the high-concentration area migrates significantly downwind from the leakage source, forming a gas cloud. In the gathering area, the area where the concentration exceeds the standard is large, and the fire risk is increased; when the atmosphere is stable, the Gaussian plume model does not consider the gas-phase oxidation reaction, the concentration is attenuated, the spread range is increased, the excessive concentration is reduced, and the fire risk is reduced. FDS is added to the derived mixed gas to form a mixed gas cloud of vinyl chloride and formaldehyde at the same time. The fire risk of the explosive mixed gas is further increased. At the same time, it is affected by the acidic mist, which is extremely harmful to evacuation and rescue operations during an emergency or accident. When the atmosphere is stable, the conclusions obtained by the two methods are essentially the same; when the atmospheric stability is poor, because the 
FDS simulation considers the gas-phase reaction, the results obtained are more confident than the former.

\section{Limitations and Future Work}

In the process of numerical simulation, a more ideal model was adopted, and only part of the working conditions was selected for preliminary research. Therefore, it still needs in-depth research and continuous improvement. Due to the high hazard of vinyl chloride and the restriction of strict experimental conditions, the corresponding experimental comparative study has not been carried out. Most of existing studies use similar alternative gases, but vinyl chloride has no good alternative gas, and the results of alternative gas are not very accurate, which still needs further exploration. In addition, the current research work was only aimed at a two-dimensional plane simulation and quantitative analysis of vinyl chloride leakage and diffusion. In subsequent research work, we will extend our study to three-dimensional simulation and visualization platform system of vinyl chloride leakage and diffusion and quickly solve the concentration field with initial and boundary conditions, division of rapid-response hazard-level areas, and further emergency rescue management and personnel evacuation in line with the actual scene.

\section{Conclusions}

In this paper, the numerical analysis software MATLAB was used to study the influence of the atmospheric stability described by the Gaussian plume model on the leakage and diffusion of vinyl chloride. FDS was used to investigate the presence or absence of the gas-phase oxidation reaction of vinyl chloride and the derived gas cloud under different classes of atmospheric stability. We considered the law of diffusion and the comparative analysis of the risk of leakage and diffusion. The research in this article also provides some references for guiding an emergency response to vinyl chloride leakage accidents and on-site evacuations and rescues. Through the analysis in this article, the following main conclusions can be drawn.

- Under the Gaussian plume model, as the degree of atmospheric stability tends to be stable, the diffusion concentration area of the vinyl chloride vapor cloud transitions from an ellipse with a smaller focal length to an oblong ellipse, the peak concentration decreases accordingly, and the fire risk area gradually shrinks. The fire hazard decreases, the affected area gradually expands, and the toxic hazard increases.

- When the atmospheric environment is unstable, the conversion rate of the gas-phase oxidation reaction to form formaldehyde is increased. After vinyl chloride leaks, it accumulates. Although the impact range is small, the toxic formaldehyde has a stronger agglomeration effect and is difficult to handle, the concentration of harmful gases in the region is higher, and the fire hazard of the mixed gas is increased.

Author Contributions: Conceptualization, Y.L. and J.W.; methodology, Y.L.; software, Y.L.; validation, Y.L. and J.W.; formal analysis, Y.L. and J.W.; investigation, Y.L.; resources, Y.L.; data curation, Y.L.; writing —original draft preparation, Y.L. and J.W.; writing—review and editing, Y.L. and J.W.; funding acquisition, J.W. All authors have read and agreed to the published version of the manuscript.

Funding: This research was funded by the National Natural Science Foundation of China, grant number 51991352; the Key Research and Development Program of Yunnan Province, China, grant number 202003AC100001; and the National Key Research and Development Program of China, grant number 2018YFC0808600.

Institutional Review Board Statement: Not applicable.

Informed Consent Statement: Not applicable.

Data Availability Statement: The data presented in this study are available on request from the corresponding author.

Conflicts of Interest: The authors declare no conflict of interest. 


\section{References}

1. Dana, L.I.; Burdick, J.N.; Jenkins, A.C. Some physical properties of vinyl chloride. J. Am. Chem. Soc. 2002, 49, 2801-2806. [CrossRef]

2. Zhao, E.K.; Ji, D.F. Petrochemical equipment maintenance process safety management. Chem. Eng. Des. Commun. 2018, 133. [CrossRef]

3. Chen, W.; Zhang, X.; Management, D.O. Excavation of key risk factors based on apriori algorithm for fire and explosion in storage and transportation of hazardous chemicals. Fire Saf. Sci. 2017, 26, 133-139.

4. Jafari, M.J.; Bahmani, R.; Poyakian, M.; Behzadi, Y.K.; Khodakrim, S. Modeling the consequence of vinyl chloride accidental release from tanks in a petrochemical plant. Occup. Hyg. Health Promot. 2021, 4, 301-314. [CrossRef]

5. Suciu, I.; Prodan, L.; Ilea, E.; Păduraru, A.; Pascu, L. Clinical manifestations in vinyl chloride poisoning. Ann. N. Y. Acad. Sci 2010, 246, 53-69. [CrossRef] [PubMed]

6. Long, L.A.; Lay, J.; Leskin, K.; McClure, R.; Smith, A. Vinyl chloride monomer explosion. Process Saf. Prog. 2008, 27, 72-79. [CrossRef]

7. Xiao, F. The Ministry of Emergency Management requires resolute prevention and containment of major accidents. China Fire 2018, 517, 6-7.

8. Huang, J.L.; Zhu, G.Q.; Meng-Wei, Y.U. Quantitative hazard analysis of ammonia leakage and diffusion based on cfd. Fire Sci. Technol. 2015, 34, 812-815.

9. Wang, D.; Zhao, J.P.; Liu, D.H.; Wen, L.I. Simulation of liquid ammonia storage tank leakage diffusion based on gaussian model Environ. Eng. 2016, 34, 140-144.

10. Liu, Y.; Li, X.X.; Luo, Y.X.; Bai, L.S.; Yang, Z. Simulation and analysis of vinyl chloride tank leakage accident based on ALOHA software. China Emerg. Rescue. 2019. CNKI: SUN: YJJY.0.2019-05-006.

11. Xing, Z.; Li, J.; Wu, J. Numerical simulation of leakage and diffusion characteristics of vinyl chloride based on fluent. J. North China Inst. Sci. Technol. 2019. CNKI: SUN: HBKJ.0.2019-05-010.

12. Anonymous. Research on combustible gas disasters by Japan Fire Research Institute. Fire Sci. 2002, 11, 151.

13. Sun, L.; Zhao, Y.; Cao, F.; Ye, M. Analysis and comparison of research status of hazardous chemical leakage and diffusion models. Chin. Saf. Sci. J. 2011, 21, 37-42.

14. Majumdar, D.; Bhanarkar, A.; Gavane, A.G.; Rao, C. Measurements on stationary source emissions and assessing impact on ambient air quality around two Indian refineries. Asian J. Atmos. Environ. 2019, 13, 73-87. [CrossRef]

15. Berens, A.R. Diffusion and relaxation in glassy polymer powders: 1. Fickian diffusion of vinyl chloride in poly (vinyl choride) Polymer 1977, 18, 697-704. [CrossRef]

16. Gilmore, P.T.; Falabella, R.; Laurence, R.L. Polymer/polymer diffusion. 2. Effect of temperature and molecular weight on macromolecular diffusion in blends of poly (vinyl chloride) and poly( $\varepsilon$-caprolactone). Macromolecules 1980, 13, 880-883. [CrossRef]

17. Li, Y.Y. Improvement of Gaussian Plume Model and Its Application in the Simulation of Hazardous Chemical Leakage Accidents; Guangzhou University: Guangzhou, China, 2013.

18. Meng, Q.Z. Research on Several Issues in National Standards for Atmospheric Stability Classification. J. Chengdu Univ. Inf. Technol. 2003, 18, 393-397. [CrossRef]

19. Pasquil, F. The Estimation of the Dispersion of Windborne Material. Aust. Meteorol. Mag. 1961, 90, 33-49.

20. Turner, D.B. Workbook of Atmospheric Dispersion Estimates: An Introduction to Dispersion Modeling; CRC Press: London, UK, 2020. [CrossRef]

21. Carassiti, V.; Chiorboli, C.; Bignozzi, C.A. Atmospheric photo-oxidation of vinyl chloride: A generalized treatment of the relative rates of product formation. Ann. Chim. Sci. Mater. 1977, 47, 499-512. 